\title{
Understanding Abundance of Litter on Urban Lake in Developing Country: a Systems-thinking Approach
}

\author{
Muhammad Muhsin ${ }^{1, *}$, Mahawan Karuniasa ${ }^{1}$, and Herr Soeryantono ${ }^{2}$ \\ ${ }^{1}$ School of Environmental Science, Universitas Indonesia, Indonesia \\ ${ }^{2}$ Civil Engineering Department, Faculty of Engineering, Universitas Indonesia, Indonesia
}

\begin{abstract}
An abundance of litter on urban lake environment has been an issue for decades. This complex issue involves many stakeholders and also couples human socio-economic and natural-environment systems. Understanding the interrelationships among stakeholders and between those two systems is important as a first step for looking the solutions. This paper aims to present a systems-thinking approach to illustrate the relationships among key factors contributing to the issue. We examined Kenanga Lake located on Campus of Universitas Indonesia, Depok City, Indonesia and some part of its catchment area as a pilot project. By conducting field observation and previous literature review, we identified that campus management, municipal government, and citizen are three major stakeholders in the systems. The results showed that lake cleanness contributes to campus image, thus it gives feedback to the city's economic and population growth. In another side, those growths combined with some socio-cultural aspects have a pathway to perpetuate this problem. The interrelationships among those factors are further illustrated by a conceptual diagram. Finally, this holistic approach diagram can be used to inspire the development of dynamic models for helping decision making.
\end{abstract}

\section{Introduction}

Lake is one of freshwater ecosystem that essential for human life. Because of its significant role, usually, it is not owned by private but it is classified as Common Property Resources (CPR). Unfortunately, in developing country, CPR is still poorly managed which was renowned as "the tragedy of the commons" [1]. In urban setting, urban lake ecosystem is one of them [2].

For decades, previous studies showed that human activities, especially urban development, have been threatening the existence of urban lakes [2-5]. They received polluted water from its surrounding urban environment watershed which led to sedimentation and degradation of its water quality. Anthropogenic litter is one of the contaminants accumulated in the lakes that difficult to manage [6-8].

\footnotetext{
${ }^{*}$ Corresponding author: muhammad.muhsin.89@gmail.com
} 
In developing country, e.g. Indonesia, this abundance of litter problem is still an unsolved environmental issue that tends to get worst [3]. This complex issue involves many stakeholders and also couples human socio-economic and natural-environment systems. In order to reach a sustainable solution of lake ecosystem related issue, coupling socio- economic and lake systems is required [9]. However, in case of litter abundance on urban lake in developing country, its unique interrelationships between those two systems still remain unclear. So, this study tries to understand the interrelationships among stakeholders and between those two systems as a first step for looking the solutions.

Considering the interdependent of social-ecological systems of the problem, we applied a systems-thinking approach to get a holistic systems perspective. A systems-thinking approach was known as a reliable tool for unraveling a complex issue [10]. It has been used in a number of studies and various research themes, e.g. behavioral change, social- ecological systems, and paradigm shifts [11] .Yet, there is a gap to exercise this approach in the case of abundance of litter on urban lake in developing country. Therefore, this paper aims to present a systemsthinking approach to illustrate the relationships among key factors contributing to the issue.

Here, we investigate Kenanga Lake - an urban lake located on Campus of Universitas Indonesia in Depok City, Indonesia - as a pilot project. Kenanga Lake and several urban lakes inside the campus play important roles, e.g.: groundwater recharge, flood control, water supply, and natural research facility [12]. In spite of its essential roles, it has been polluted by citizen activities lived in lakes catchment area [5]. Litter abundance on the lake is one of its threats. Trash trap was installed on the Inlet of Kenanga Lake to overcome this issue. However, its capacity has been exceeded due to high load of urban litter. Besides, the operational cost tends to increase which become another problem for campus management.

\section{Materials and Methods}

This study is an explorative-qualitative research which consists of two major processes: problem structuring and model conceptualization ${ }^{[13]}$. First, we reviewed a number of previous researches related to systems-thinking approach in various themes. Then, we observed existing research relevant to this topic. Inspired by these literature reviews, we built a hypothetical conceptual interrelationship diagram. Afterward, we conducted field observation to see how a real complex world works. Figure 1 shows our pilot project area exploration which was a hypothetical catchment area of Kenanga Lake. Besides, to shed light on our observation finding, we also gather information from related stakeholders through an informal interview. Finally, we reconstructed the hypothetical diagram and synthesized a conceptual diagram of the issue, based on the holistic observation of the area.

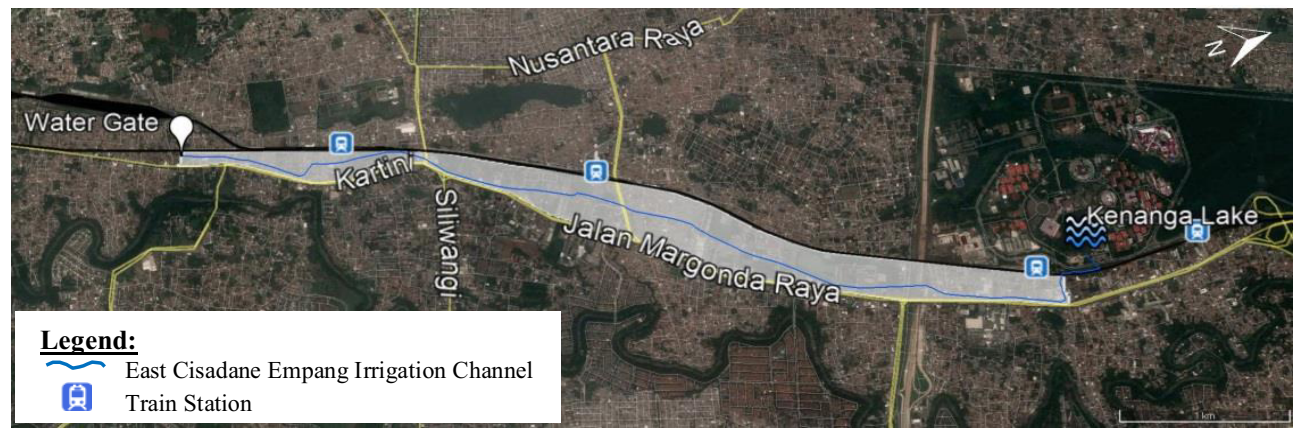

Fig. 1. Observed pilot project location—surrounding area adjacent to East Cisadane Empang Irrigation Channel, Depok City, West Java, Indonesia. 


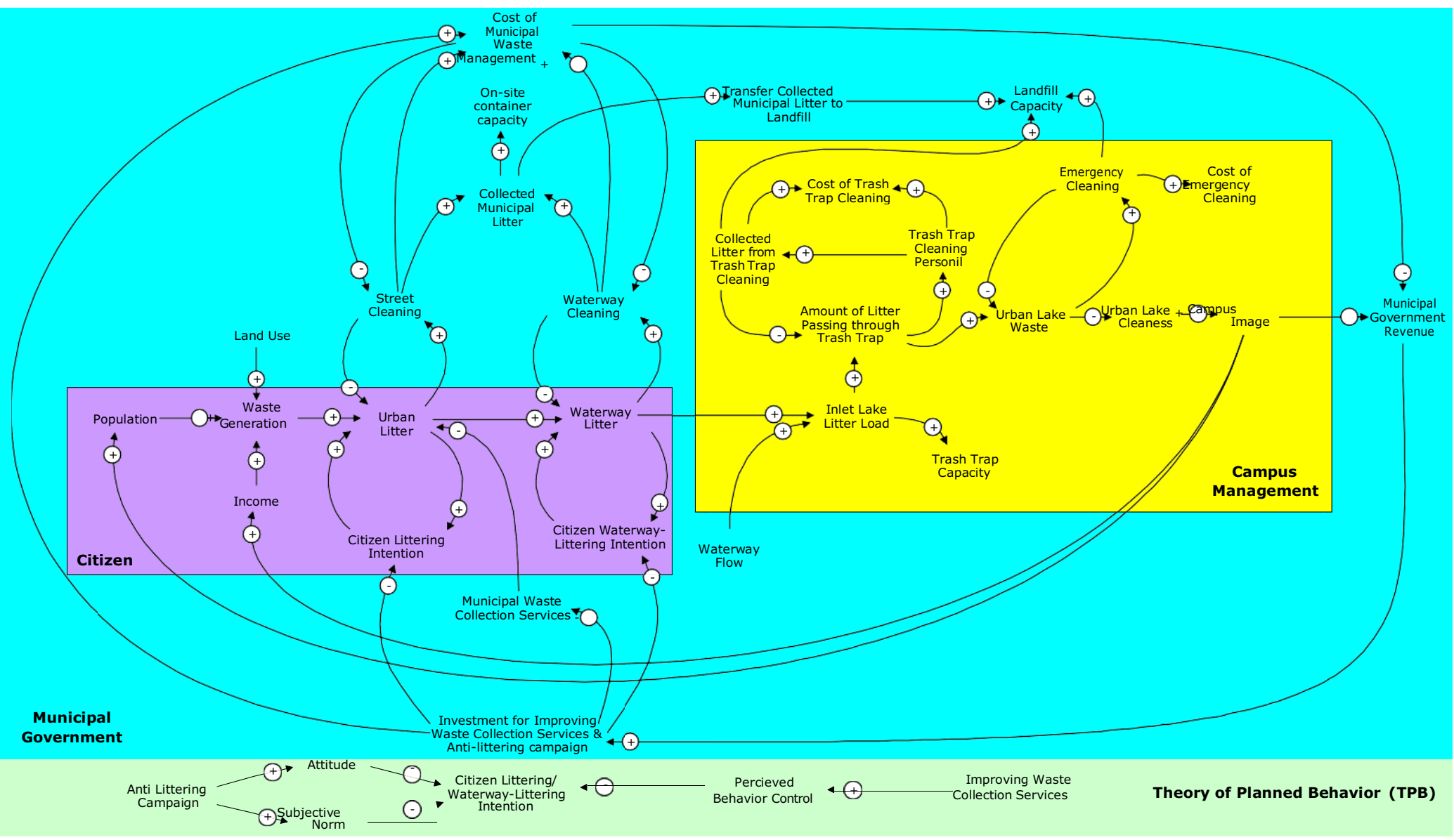

Fig. 2. The conceptual diagram of litter abundance on the urban lake using a systems-thinking approach. 


\section{Results and Discussions}

From our literature reviews, we found that research related to systems-thinking approach can be classified based on its theme, objective, scope and supporting method. Regarding our topic, it lies in the middle of two major themes: waste management theme and water resources management theme. In this study, we focused on applying this approach to understanding a local-scope problem. A study of litter abundance on Kuta Beach, Bali is one of the gems inspired this research [14]. Besides, recent studies that combined it with Planned Behavior Theory of Ajzen showed a satisfying result in explaining the social phenomenon of the systems $[15,16]$. Therefore, we considered to exercise it in our study.

Moreover, our observation and interview showed some interesting facts. First, a few decades ago, Kenanga Lake used to get unpolluted water from East Cisadane Empang Irrigation Channel. As the city was developed gradually, the input was also getting worst little by little. Today, it's no longer served as an irrigation channel, but as an urban drainage. Second, Kemiri Muka traditional market area located adjacent to the channel has contributed a significant amount of litter to the lake. Its unorganized layout, poor waste management, and bad drainage condition appear to cause the abundance of litter in the area which is flowed by runoff into a waterway. Third, while the municipal government tries to clean up the channel regularly, citizen behavior to litter or dump their waste directly to the channel is an everyday phenomenon. Finally, we identified that citizen, municipal government and campus management are three major stakeholders in the systems.

Furthermore, a conceptual diagram was established based on previous literature reviews and observation findings (see Figure 2). It describes the interrelationship of key components among the stakeholders, as reviewed briefly below.

Campus management. Located exactly in the heart of the campus, it's obvious that lake cleanness is related to campus image [17]. Good campus image has brought a multiplier effect to the city's economic and population growth [18]. Tax growth also indicates this positive feedback (see Figure 3). However, the increasing trend of inlet lake litter load has put a burden on campus management in terms of lake cleaning cost. Besides, even though the trash trap helps to regulate the urban lake waste, eventually its capacity will be exceeded because of the litter growing trend. Limited space is another issue in expanding its capacity. Moreover, more urban lakes litter also gives more pressure to landfill capacity.

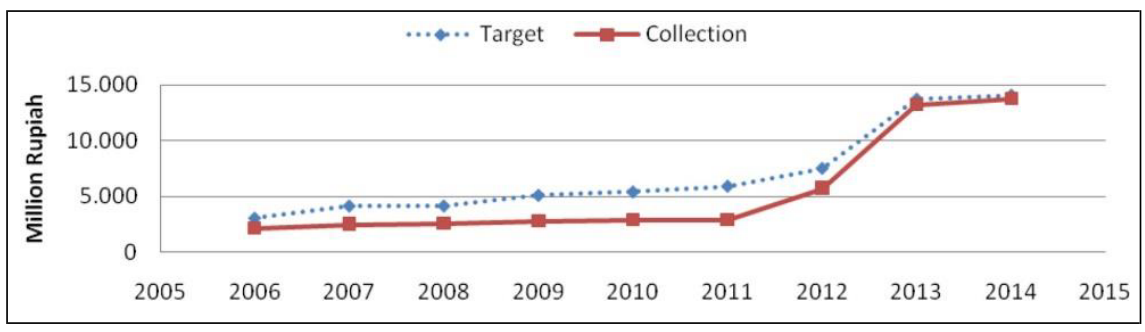

Fig. 3. Municipal government revenue from land and building tax.

Citizen. As waste generation tend to grow up, behavior change plays important roles in controlling amount of litter. It's crystal clear that more population and higher income, more waste generated and-as long as littering behavior exist-it increases urban litter and waterway litter [19]. Adjusting the frequency of street cleaning and waterway cleaning is a reactive way to solve it. However, limited municipal waste management cost and landfill capacity are important factors that need to be considered in municipal government side. 
Municipal Government. Long term effort to change citizen's behavior needs to be put as a priority in government budgeting process. Planned behavior theory of Ajzen shows how an effective anti-littering campaign and improving waste collection services can changepeople's littering intention by altering their attitude, subjective norm and perceived behavior control $[15,16]$. In practice, the government can work together with surrounding higher education institution whose role is as an agent of change in the society, e.g.: Universitas Indonesia and Universitas Gunadharma.

\section{Conclusions}

In a nutshell, the systems-thinking approach can help us further our understanding of the abundance of litter on urban lake phenomenon. The conceptual diagram captures that beneficiaries of the clean Kenanga Lake are not only campus management, but also the citizen and municipal government. Besides, citizen's littering behavior is a key component in the systems that need to be changed. In order to stop the burden on campus management, the municipal government needs to put the budget priority on improving waste collection services and anti-littering campaign. On the other side, higher education institution role as the agent of change should be maximized, so that the citizen behavior will improve progressively. Furthermore, this holistic approach diagram can be used to inspire the development of dynamic models for helping decision making.

\section{Acknowledgments}

This research is supported by Hibah PITTA 2018 funded by DRPM Universitas Indonesia No.2580/UN2.R3.1/HKP.05.00/2018.

\section{References}

1. G. Hardin, Sci. N. S. 162 (1968).

2. J. Persson, Encyclopedia of Lakes and Reservoirs (Springer, Dordrecht, 2012)

3. C. Henny, A. A. Meutia, Procedia Env. Sci. 20, 737 (2014) 4.K. Chen, X. Wang, D. Li, Z. Li, Eco. Mod 318, 204(2015)

4. D. Sutjiningsih, E. Anggraheni, Proceeding of the 12th International Conference on Quality in Research, 2308 (2011)

5. T. Hoellein, M. Rojas, A. Pink, J. Gasior, J. Kelly, PLOS ONE 9, 6 (2014)

6. A.G.J.Driedger, H.H.Dürr, K.Mitchell, P.VanCappellen, J.Gr.Lakes Res. 41, 9 (2015)

7. A. E. S. Vincent, T. J. Hoellein, J. Cont. Wat. Res. \& Edu. 160, 72 (2017)

8. G. Mavrommati, M. M. Baustian, E. A. Dreelin, AMBIO 43, 275 (2014)

9. J. D. Sterman, Business dynamics: Systems Thinking and Modeling for A Complex World (McGraw-Hill, New York, 2000)

10. A. Williams, S. Kennedy, F. Philipp, G. Whiteman, J. Cl. Pro. 148, 866 (2017)

11. N. Suwartha, R. A. Pramadin, Makara Tech. 16, 1(2012)

12. S. El Sawah, A. McLucas, M. Ryan, Proceeding of the 18th IEEE International Requirements Engineering Conference, 357(2010)

13. A. Yunanto, E. Suganda, T.E.B. Soesilo, A. Hanggono, Int. J. Sci.Bas. App. Res 15, 708 (2014) 
14. H.Guo, B.F.Hobbs, M.E.Lasater, C.L.Parker, P.J.Winch, Was.Man. 56, 547 (2016)

15. Z. Ding, G. Yi, V. W. Y. Tam, T. Huang, Was. Man. 51, 130 (2016)

16. G. Tjahjono, E. Suganda, D. Sigit, B. A. Sukada, S. Somadikarta, Kampus Universitas Indonesia (UI-Press, Jakarta,2002)

17. T. W. Mudaryanti, SASDAYA Gadjah Mada J. Hum. 1, 113 (2016)

18. N. Armitage, Urb. Wat. J. 4, 151 (2007)

19. M.Y. Rahmaddin, T. Hidayat, B. Yanuwiadi, Suyadi, Int. J. App. Psy. 5, 96 (2015) 